\title{
IMPLANTAÇÃO DO ESCRITÓRIO DE PROJETOS COMO ESTRATÉGIA DE GESTÃO INTEGRADA NAS MINAS DA DIRETORIA DE FERROSOS SUDESTE*
}

\author{
Erton Andrade Vieira ${ }^{1}$ \\ Fábio Lucas Silva² \\ João Marcelo Tarbes Vianna Mendes ${ }^{3}$ \\ Marcio José Campos Borba ${ }^{4}$ \\ Thales Vinicius Gomes de Assis ${ }^{5}$ \\ Ana Paula de Paiva Costa \\ Andrea de Oliveira Furtado ${ }^{7}$ \\ Efigenio Rodrigues da Costa Junior ${ }^{8}$
}

Resumo

A cotação do minério de ferro caiu muito nos últimos anos. Em função disto, a Vale buscou se adaptar para continuar atendendo às condições do mercado. Considerando que o principal cliente mundial atualmente é a China, que os principais concorrentes estão na Austrália, e que as suas operações deste produto estão localizadas no Brasil, os desafios da Vale têm sido cada vez maiores para se produzir com qualidade e com baixo custo. Com este cenário, o desdobramento da estratégia da empresa, bem como sua execução, têm merecido destaque especial na Diretoria de Ferrosos Sudeste. Em meio a este momento, foi implantado - Escritório de Projetos, que recebeu a responsabilidade pela condução do planejamento estratégico, desdobramento da estratégia e gestão de carteira de projetos nessa Diretoria, de forma integrada com outros pilares da Gestão da Qualidade.

Palavras-chave: Gestão Integrada; Escritório de Projetos; PDCA; Planejamento Estratégico.

\section{IMPLEMENTATION OF THE PROJECT MANAGEMENT OFFICE AS AN INTEGRATED MANAGEMENT STRATEGY IN THE MINES OF THE DIRETORIA DE FERROSOS SUDESTE Abstract}

The price of iron ore has dropped a lot in recent years. As a result, Vale sought to adapt to continue to meet market conditions. Considering that the main worldwide customer is China, that the main competitors are in Australia, and that its operations of this product are located in Brazil, the challenges of Vale have been increasing to produce with quality and with low cost. With this scenario, the unfolding of the company's strategy, as well as its execution, have deserved special mention in the Diretoria de Ferrosos Sudeste. In the middle of this moment, the Project Office was implemented, which was given responsibility for conducting strategic planning, strategy deployment and portfolio management of projects in this Diretoria, in an integrated way with other pillars of Quality Management

Keywords: Integrated Management; Project Management Office; PDCA; Strategic Planning.

1 Graduado em Geografia, Pós Graduado em Gestão de Pessoas, Analista de Qualidade e Gestão, Gerência de Qualidade e Gestão Integrada, Vale S/A, São Gonçalo do Rio Abaixo/MG, Brasil.

2 Tecnólogo em Processos Gerenciais, Pós Graduado em Gestão Empresarial, Analista de Qualidade e Gestão, Gerência de Qualidade e Gestão Integrada, Vale S/A, Itabira/MG, Brasil.

3 Graduado em Turismo, Pós Graduado em Sistema de Gestão Integrada e Engenharia de Produção, Supervisor, Gerência de Qualidade e Gestão Integrada, Vale S/A, Mariana/MG, Brasil.

4 Graduado em Relações Públicas, Pós Graduado em Gestão de Projetos, Gestão de Pessoas e Engenharia de Processos Industriais, Analista de Qualidade e Gestão, Gerência de Qualidade e Gestão Integrada, Vale $S / A$, Mariana/MG, Brasil.

5 Graduado em Engenharia de Produção, Pós Graduado em Engenharia de Segurança do Trabalho, Analista de Qualidade e Gestão, Gerência de Qualidade e Gestão Integrada, Vale S/A, São Gonçalo do Rio Abaixo/MG, Brasil.

6 Graduação em Gestão Ambiental, Pós em Gestão Ambiental e Engenharia de Produção Enxuta. Analista de Qualidade e Gestão, Gerência de Qualidade e Gestão Integrada, Vale S/A, Mariana/MG, Brasil.

7 Graduação em Administração, Especialização em Gestão de Projetos pelo IBMEC e Especialização em Engenharia de Produção Enxuta no IETEC. Analista de Qualidade e Gestão, Gerência de Qualidade e Gestão Integrada, Vale S/A, São Gonçalo do Rio Abaixo/MG, Brasil.

8 Graduação em Engenharia Ambiental e em Ciências Biológicas pela Fundação Comunitária de Ensino Superior e Itabira, Pós-graduação em Engenharia de Segurança pela Faculdade Pitágoras. Pós-graduação em Planejamento e Gestão Ambiental pela Fundação Comunitária de Ensino Superior e Itabira. Analista de Qualidade e Gestão, Gerência de Qualidade e Gestão Integrada, Vale S/A, Itabira/MG, Brasil. 


\section{INTRODUÇÃO}

A Vale S/A é uma empresa global de mineração, cujo principal produto é o Minério de Ferro. Atualmente é um dos maiores players mundiais neste segmento, colaborando para que o Brasil seja o segundo maior produtor de Minério de Ferro, de acordo com relatório emitido pelo US Geological Survey em 2017.

Fonte: US Geological Survey (https://minerals.usgs.gov/minerals/pubs/commodity/iron_ore/mcs-2017feore.pdf)

\begin{tabular}{|c|c|c|c|c|}
\hline \multirow[b]{4}{*}{ United States } & \multicolumn{4}{|c|}{ Mine production } \\
\hline & \multicolumn{2}{|c|}{ Usable ore } & \multicolumn{2}{|c|}{ Iron content } \\
\hline & $\underline{2015}$ & $\underline{2016^{e}}$ & 2015 & $2016^{e}$ \\
\hline & 46 & 41 & 29 & 26 \\
\hline Australia & 817 & 825 & 486 & 491 \\
\hline Brazil & 397 & 391 & 257 & 254 \\
\hline Canada & 46 & 48 & 28 & 29 \\
\hline China $^{6}$ & 375 & 353 & 232 & 219 \\
\hline India & 156 & 160 & 96 & 98 \\
\hline Iran & 27 & 26 & 13 & 11 \\
\hline Kazakhstan & 21 & 21 & 12 & 12 \\
\hline Russia & 101 & 100 & 61 & 60 \\
\hline South Africa & 73 & 60 & 46 & 38 \\
\hline Sweden & 25 & 25 & 15 & 15 \\
\hline Ukraine & 67 & 58 & 40 & 35 \\
\hline Other countries & 132 & 120 & 82 & 75 \\
\hline World total (rounded) & 2,280 & 2,230 & $\overline{1,400}$ & $\overline{1,360}$ \\
\hline
\end{tabular}

Tabela 1 - Relatório de produção de Minério de Ferro por país

Internamente na Vale, a produção de Minério de Ferro divide-se geograficamente em quatro áreas (Sistemas Sudeste, Sul, Norte e Centro-Oeste). Neste artigo, as análises serão direcionadas para o Sistema Sudeste, que em 2016 foi responsável por cerca de $29 \%$ da produção total do Minério de Ferro da empresa, e que se subdivide nos Complexos Itabira, Minas Centrais e Mariana.

Fonte: Arquivo interno da Vale

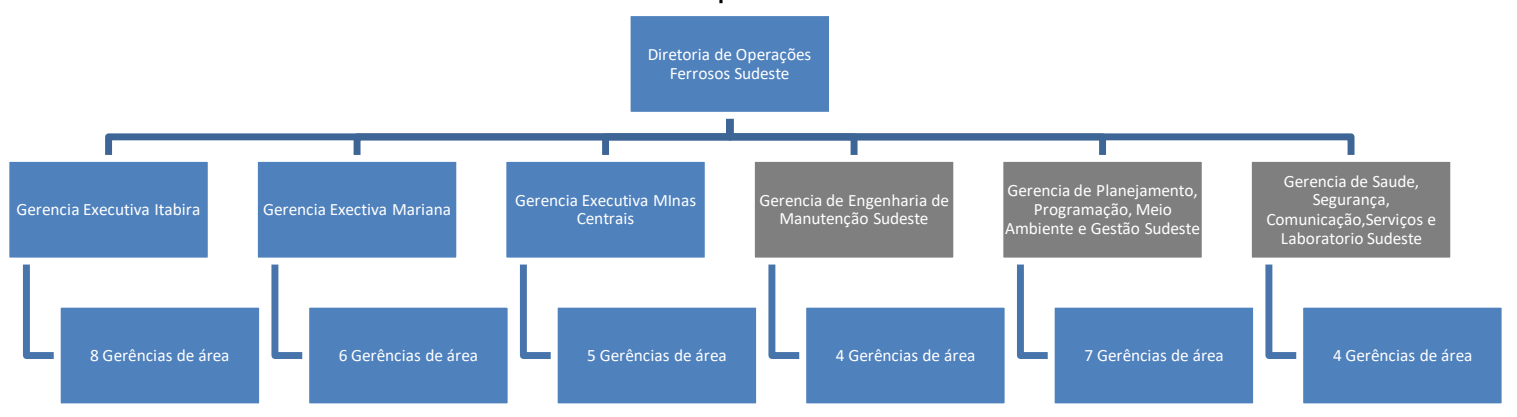

Gerências Executivas Matriciais - atuam nos 3 complexos operacionais (Itabira, Mariana e Minas Centrais).

Imagem 1 - Organograma funcional da Diretoria de Ferrosos Sudeste 
Fonte: www.vale.com/PT/investors/information-market/annual-reports/20f/20FDocs/Vale 20 -

\section{F FY2016 - p.pdf}

\begin{tabular}{|c|c|c|c|c|}
\hline Mina/Usina & Tipo & 2014 & 2015 & 2016 \\
\hline & & $(\mathrm{mi}$ & toneladas & \\
\hline \multicolumn{5}{|l|}{ Sistema Sudeste } \\
\hline Itabira & \multirow{2}{*}{$\begin{array}{l}\text { A céu aberto } \\
\text { A céu aberto }\end{array}$} & 35,8 & 35,6 & 33,4 \\
\hline 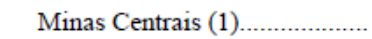 & & 33,7 & 41,3 & 40,9 \\
\hline Mariana & \multirow[t]{2}{*}{ A céu aberto } & 39,4 & 36,1 & 28,4 \\
\hline Total do Sistema Sudeste & & 108,9 & 113,0 & 102,7 \\
\hline \multicolumn{5}{|l|}{ Sistema Sul } \\
\hline Minas Itabirito & \multirow{2}{*}{$\begin{array}{l}\text { A céu aberto } \\
\text { A céu aberto }\end{array}$} & 41,0 & 41,4 & 40,1 \\
\hline Vargem Grande & & 25,0 & 29,3 & 29,2 \\
\hline 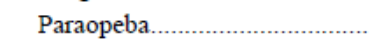 & \multirow[t]{2}{*}{ A céu aberto } & 31,2 & 28,1 & 26,4 \\
\hline Total do Sistema Sul............ & & 97,2 & 98,8 & 95,7 \\
\hline \multicolumn{5}{|l|}{ Sistema Norte } \\
\hline 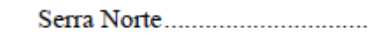 & \multirow{4}{*}{$\begin{array}{l}\text { A céu aberto } \\
\text { A céu aberto } \\
\text { A céu aberto }\end{array}$} & 117,5 & 127,6 & 143,6 \\
\hline 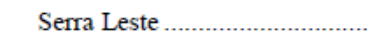 & & 2,2 & 2,0 & 4,2 \\
\hline 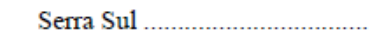 & & - & - & 0,4 \\
\hline Total do Sistema Norte ........ & & 119,7 & 129,6 & 148,1 \\
\hline \multicolumn{5}{|l|}{ Sistema Centro-Oeste } \\
\hline Corumbá & \multirow{3}{*}{$\begin{array}{l}\text { A céu aberto } \\
\text { A céu aberto }\end{array}$} & 3,8 & 2,8 & 1,9 \\
\hline Urucum & & 2,1 & 1,7 & 0,4 \\
\hline $\begin{array}{l}\text { Total do Sistema Centro- } \\
\text { Oeste }\end{array}$ & & 5,8 & 4,5 & 2,3 \\
\hline Total do Sistema Vale (2)............... & \multirow{3}{*}{ A céu aberto } & 331,6 & 345,9 & 348,8 \\
\hline Samarco (3) & & 13,1 & 12,7 & 0,0 \\
\hline Total $\ldots \ldots \ldots \ldots \ldots \ldots \ldots \ldots \ldots \ldots \ldots \ldots \ldots \ldots \ldots \ldots \ldots \ldots \ldots \ldots \ldots \ldots \ldots \ldots$ & & 344,7 & 358,6 & 348,8 \\
\hline
\end{tabular}

Tabela 2 - Relatório de produção Vale

Atualmente, o maior mercado consumidor do Minério de Ferro é a China. Em 2016, este país respondeu por $58 \%$ dos embarques de minério de ferro e pelotas da Vale. A Ásia, como um todo, respondeu por $71 \%$. O principal produto derivado deste minério é denominado "Platts 62", uma vez que o mesmo possui $62 \%$ de teor de ferro; a cotação deste produto é tida como referência nas negociações nos portos da China.

Nos últimos anos pôde-se observar uma forte queda na cotação do Platts 62, fazendo com que a margem de lucro deste produto fosse drasticamente reduzida. Em função da localização das minas de minério de ferro da Vale (todas no Brasil), o custo logístico tende a ser mais oneroso do que o dos principais concorrentes, que se localizam na Austrália. Com este cenário há uma necessidade ainda maior de redução de custos nas outras etapas da cadeia produtiva para a empresa manter-se competitiva.

Fonte: Arquivo interno da Vale

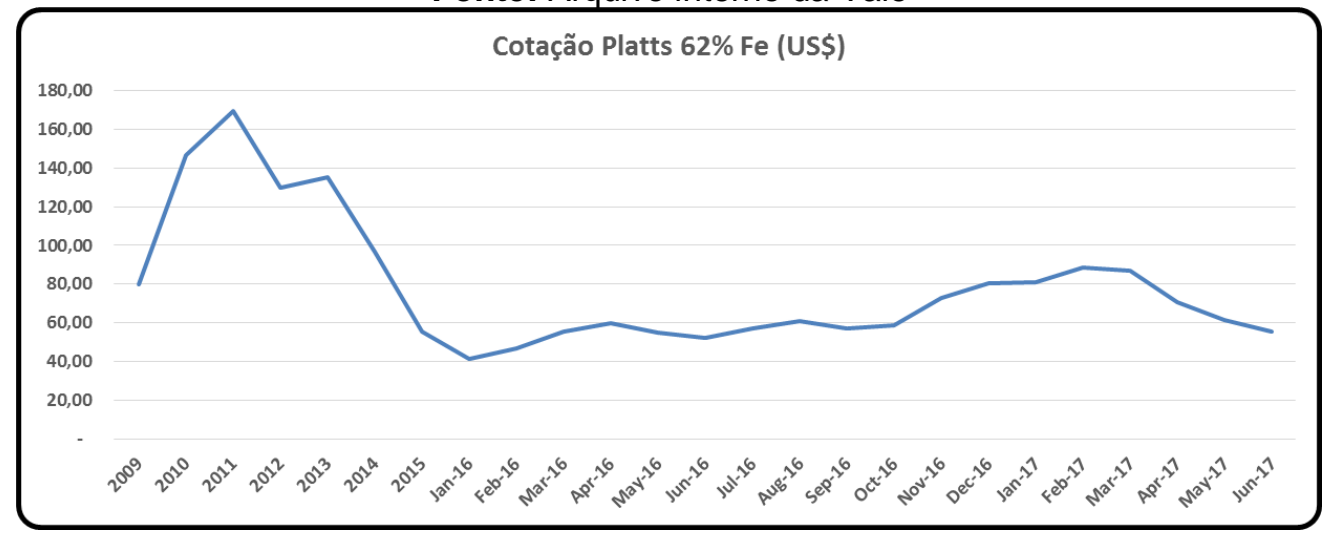

Figura 2 - Evolução da cotação do Platts 62 
Visando o alcance de processos, práticas e critérios que contemplem premissas de Qualidade Total e Gestão Ambiental, a Diretoria de Ferrosos Sudeste possui certificação na ISO 9001 - Requisitos para sistema de Gestão da Qualidade e na ISO 14001 - Requisitos para Sistema de Gestão Ambiental. A Gerência de Qualidade e Gestão Integrada é responsável por coordenar o processo de auditorias, certificação e manutenção dessas normas, bem como orientar as áreas nas implementações dos requisitos das mesmas. Além disto, esta mesma gerência é responsável pelos Programas Participativos (CCQ - Círculo de Controle da Qualidade, Programa de Ideias e 6 Sigma). Em 2015, a gerência ampliou seu escopo de atendimento às áreas operacionais da Diretoria, implantando o Escritório de Projetos, que foi criado em consonância aos pilares da Gestão Integrada, e tem em seu escopo a elaboração do planejamento estratégico, desdobramento da estratégia e gestão de carteira de projetos, bem como a orientação metodológica dos mesmos, junto aos coordenadores de cada projeto, sob a forma de consultoria interna e capacitação desses coordenadores em Seis Sigma, Lean, PDCA, Gestão de Projetos e etc.

\section{MATERIAIS E MÉTODOS}

Em sua obra, Aguiar (2006) relata que o plano estratégico é fundamental para que as empresas possam sobreviver, direcionando-as para atender às necessidades dos clientes. Este plano é o principal norteador para a definição de metas, e consequentemente, dos objetivos, projetos e iniciativas a serem desenvolvidos.

Carpinetti (2000) complementa essa visão, afirmando ser necessário o desdobramento de decisões estratégicas em projetos de melhoria nas áreas operacionais, com o intuito de alinhar os recursos e processos da empresa à sua estratégia. Segundo ele, a priorização das dimensões competitivas do negócio é baseada nas expectativas dos clientes e no posicionamento da empresa no mercado, portanto a seleção dos processos deve considerar o grau de inadequação e impacto nos indicadores estratégicos; os projetos de melhoria indicados neste desdobramento devem contribuir para a estratégia e para alavancar o desempenho dos processos críticos.

Desde sua implantação na Diretoria de Ferrosos Sudeste, em 2015, o Escritório de Projetos tem sido um importante meio de gestão para canalizar esforços rumo à melhoria contínua, de forma a se alcançar a estratégia proposta pela empresa.

Nos anos de 2016 e 2017, o processo de desdobramento de diretrizes foi reestruturado pelo Escritório de Projetos, usando como referência teórica a obra "Fazendo acontecer a coisa certa", de Pascal Dennis (2007), onde utilizou-se como ponto de partida um mapa estratégico alinhado às diretrizes da Vale, de forma a direcionar as iniciativas para se atingir esta estratégia. Os pilares definidos naquele momento eram "Segurança \& Saúde", "Produção / Qualidade", "Margem" e "Imagem". 
Fonte: Adaptado de arquivo interno da Vale

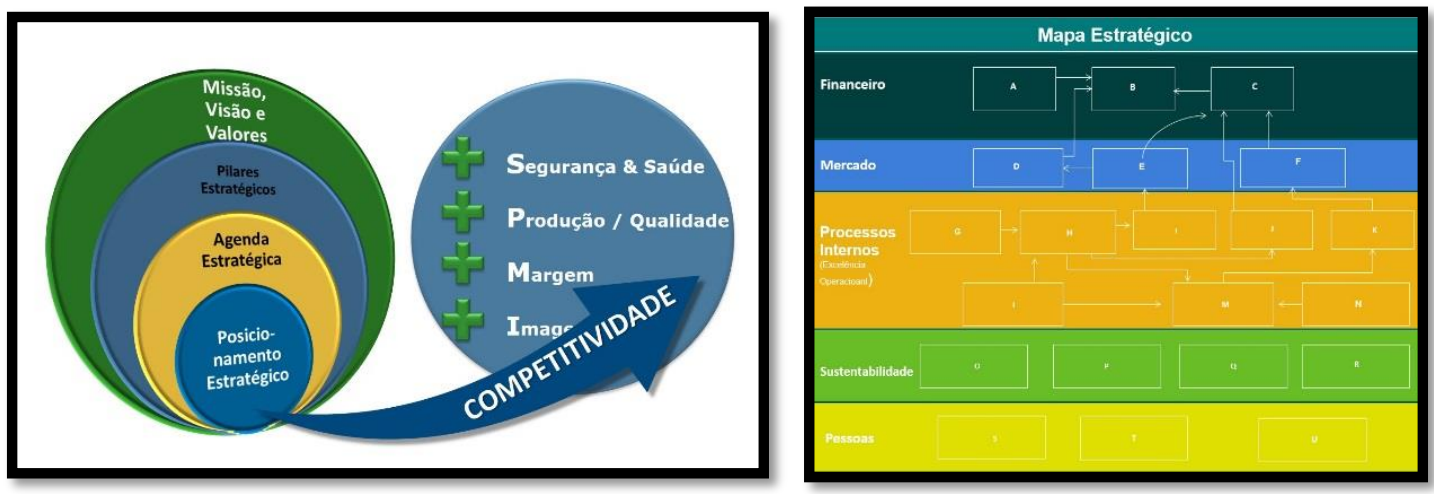

Figuras 3 e 4 - Desdobramento de estratégia de Ferrosos Sudeste em 2015

\section{RESULTADOS E DISCUSSÃO}

Ao realizar o estudo com base no conceito de hoshin kanri, abordado por Dennis (2007), em que um modelo de gestão deve ter seu propósito e estratégia bastante claros, processos enxutos com fluxo de valor horizontal e pessoas engajadas na estratégia, fazendo uso da melhoria contínua, foi definida uma proposta de trabalho estruturada com os seguintes passos:

1) Avaliação das lições aprendidas do ciclo anterior;

2) Proposta para o próximo triênio (direcionamento das áreas reguladoras quanto aos principais indicadores estratégicos; maior sinergia do mapa estratégico com indicadores operacionais; potencialização de foco da equipe técnica para aproveitamento de referências por processo e desdobramento de metas da organização de forma alinhada com a estratégia);

3) Validação do Plano Diretor para os próximos 5 anos, considerando riscos do negócio, principais KPIs e premissas;

4) Definição dos modelos e formatos de material a serem utilizados por cada área;

5) Elaboração de material considerando os principais desafios atuais de cada área (desvios, riscos e lacunas de atingimento de metas), utilizando ferramentas da qualidade (SWOT e Relatório 3 gerações), tendo um A3 como produto;

6) Validação das análises apresentadas nas gerências de área;

7) Realização de RAE (Reunião de Análise Estratégica) em cada Gerência Executiva, com participação dos gerentes executivos, gerentes de áreas operacionais, áreas reguladoras e staffs estratégicos, com objetivo de validar as saídas levantadas a partir das premissas e análises das áreas reguladoras (Gestão Econômica, Meio Ambiente, Segurança, Saúde, Produção e Qualidade, RH e Comunicação);

8) Validação do A3 de cada Gerência Executiva junto ao Diretor, incluindo os indicadores direcionadores para o próximo triênio;

9) "Catchball" - Integração de processo, agrupando os problemas/projetos por cada área, identificação de sinergia/incompatibilidade de projetos entre áreas, criação de grupos técnicos para buscar solução dos problemas levantados;

10) Classificação e direcionamento das saídas principais do $A 3$;

11) Gestão do andamento das saídas e sua eficácia; 
12) Retroalimentação do A3 previamente construído e consolidação de produto: levantamento de problemas pelas áreas, tendo como base os pilares estratégicos da Diretoria de Ferrosos Sudeste;

Ao final deste processo, passou-se a ter um material estratégico com as principais ações a serem tomadas, de forma a garantir o atingimento das metas. Essas iniciativas foram então classificadas entre: 1) projetos e melhorias e 2) gestão de rotina. Classificação esta que foi realizada de maneira integrada, e que se tornou fundamental para que fosse possível direcionar a ação adequada em cada caso.

O Escritório de Projetos assumiu então a orientação metodológica para os projetos indicados, sendo estes derivados em quatro formas de tratamento: Gestão de Projeto (utilizando-se princípios do PMBok), Lean/VPS na Prática, 6 Sigma ou PDCA.

Aqueles temas que deveriam ser tratados como gestão da rotina, foram direcionados para a equipe de SGI - Sistema de Gestão Integrada, que passou a orientar as áreas sobre quais as melhores formas de se tratar as anomalias identificadas, tais como ações preventiva/corretivas, gestão de mudanças entre outras.

Projetos com menor complexidade foram indicados para serem tratadas por grupos de CCQ - Círculo de Controle da Qualidade, Programa de Ideias ou outras formas sob gestão de cada uma das áreas operacionais.

Para permitir a gestão integrada deste portifólio de projetos, foi desenvolvido um sistema, ao qual foi atribuído o nome "Portal Melhoria Contínua"

Fonte: Arquivo interno da Vale

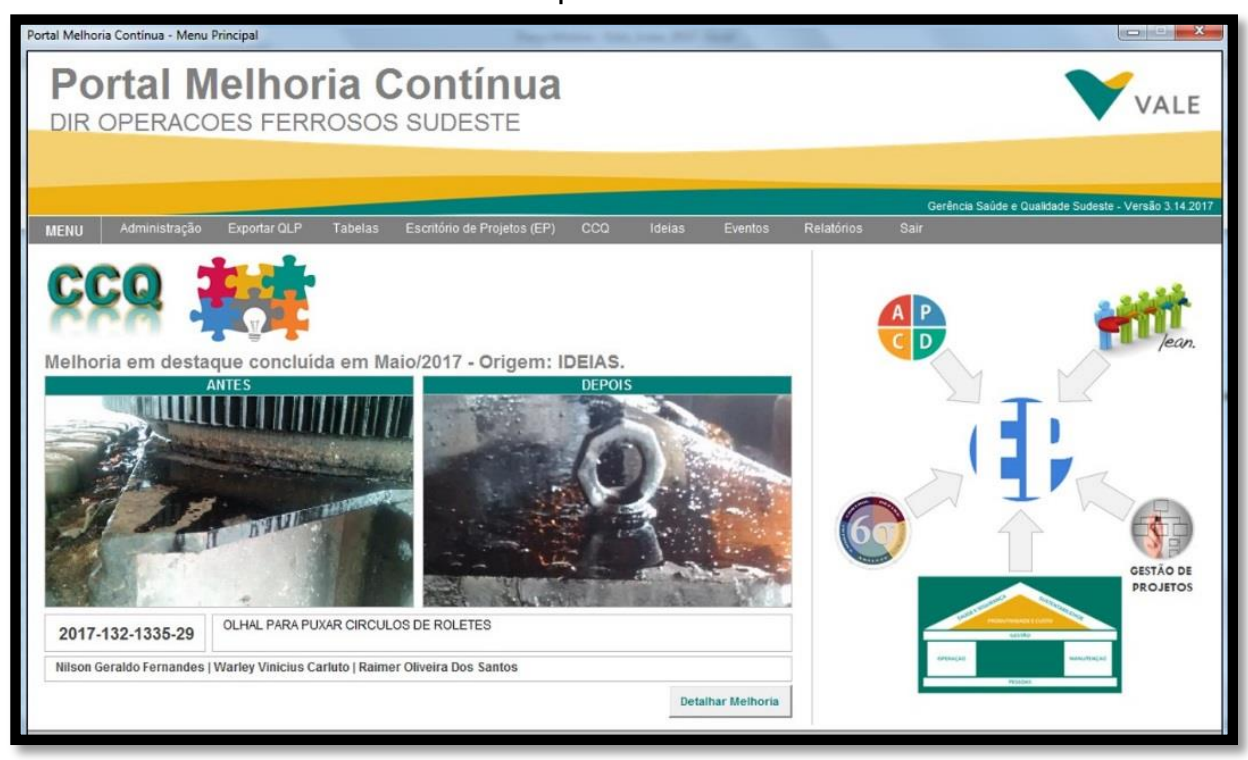

Figura 5 - Portal Melhoria Contínua

Dentre outras vantagens, este sistema permite cadastrar Relatórios de Visita Técnica (RVT) para relatar o que foi abordado/orientado em cada reunião de consultoria com os coordenadores dos projetos do Escritório de Projetos e líderes de grupos de CCQ, gerar relatórios de todos os projetos cadastrados, assim como farol de indicadores para acompanhamento gerencial. Para os tratamentos de não conformidades e 
anomalias de rotina - processo conduzido pela equipe de SGI - utiliza-se o SAP como ferramenta de gestão, e, caso seja diagnosticada a necessidade de abertura de um novo projeto para tratamento complementar destas anomalias, o mesmo segue para o Portal Melhoria Contínua, integrando a gestão do portifólio.

Fonte: Arquivo interno da Vale

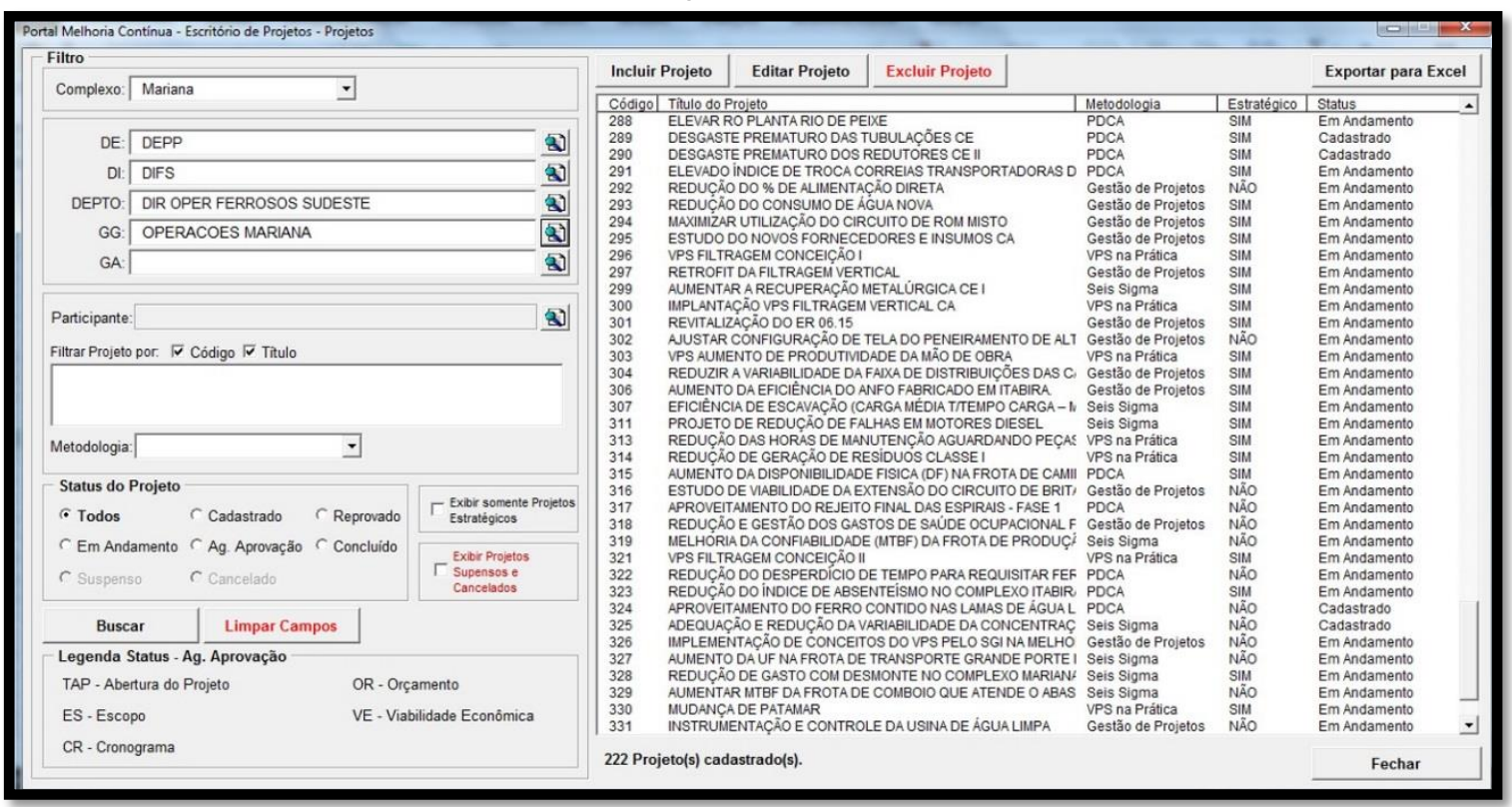

Figura 6 - Portal Melhoria Contínua

Com a implantação do Escritório de Projetos, pode-se mensurar alguns dados de 2015 até os dias de hoje, conforme abaixo:

Fonte: Portal Melhoria Contínua

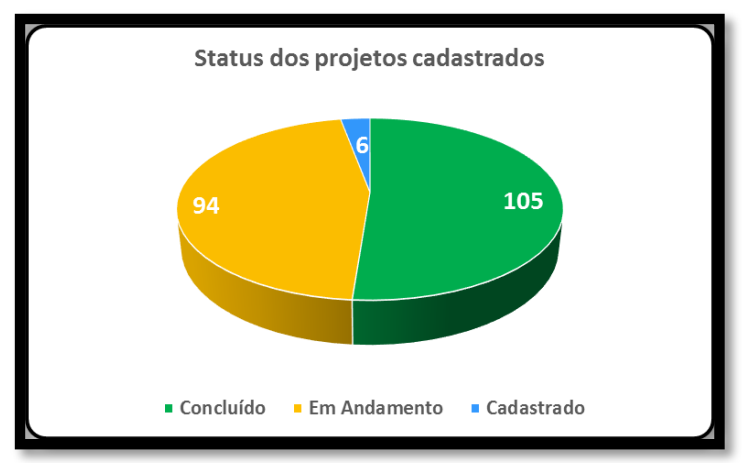

Figura 7 - Status dos projetos cadastrados no Portal Melhoria Contínua - 2015/2017 (até maio/17) 
Fonte: Portal Melhoria Contínua

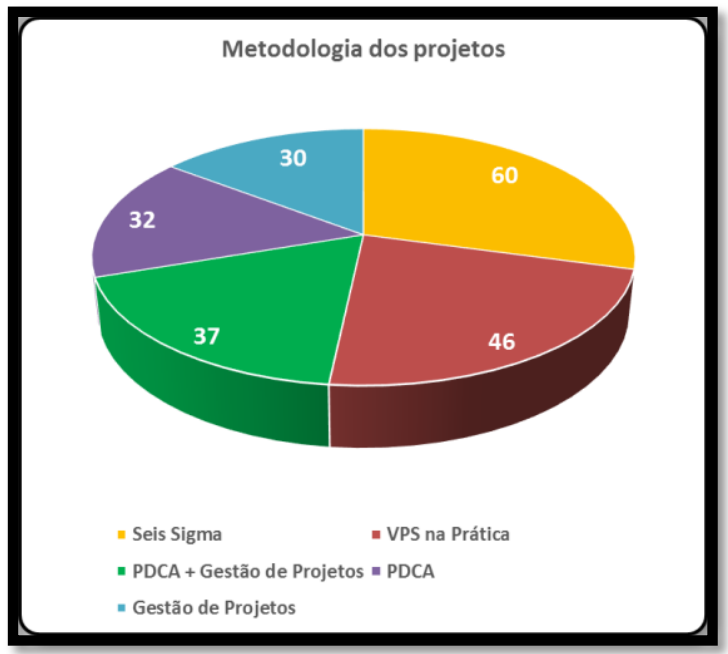

Figura 8 - Metodologia dos projetos cadastrados no Portal Melhoria Contínua - 2015/2017 (até maio/17)

Fonte: Portal Melhoria Contínua

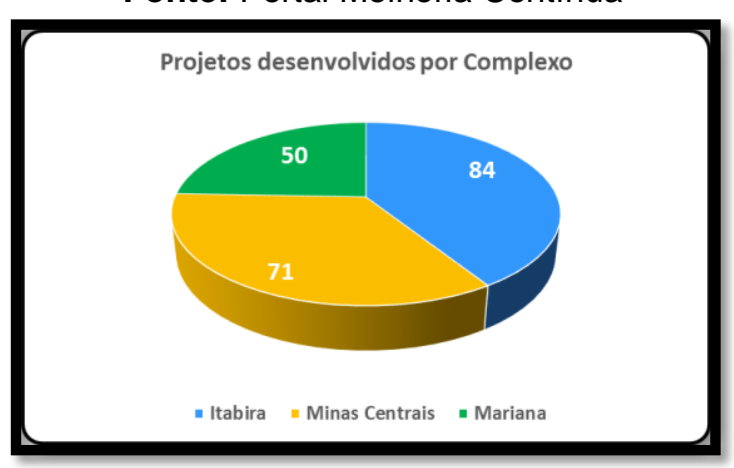

Figura 9 - Projetos cadastrados no Portal Melhoria Contínua, agrupados por Complexo Minerador 2015/2017 (até maio/17)

Fonte: Arquivo Interno da Vale

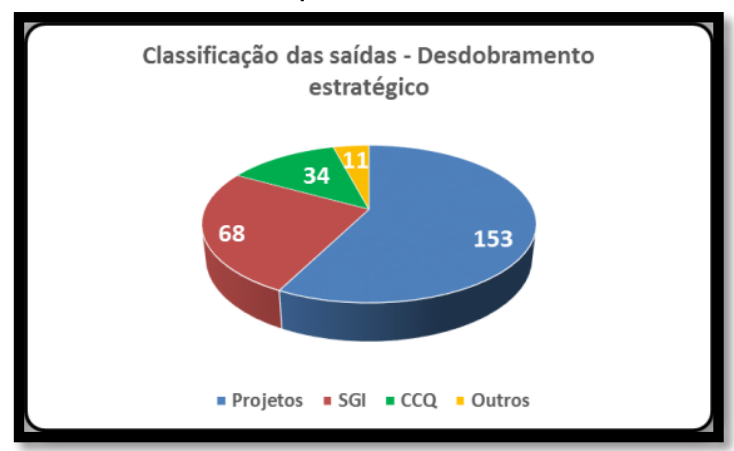

Figura 10 - Classificação dos desdobramentos da Reunião Estratégica da Diretoria de Ferrosos Sudeste em 2017 


\section{CONCLUSÃO}

A partir da implantação do Escritório de Projetos tem-se hoje uma visão mais integrada e abrangente quanto ao cenário da empresa e os alvos a serem alcançados. Importante ressaltar que o trabalho sobre oportunidade e ameaças trouxe uma nova ótica, saindo da situação reativa dos processos e atuando agora sob uma forma mais preventiva. A rotina de acompanhamento dos projetos através de consultorias faz com que os coordenadores dos projetos tenham disciplina na execução para garantir que os mesmos atinjam os propósitos (prazo, custo, tempo, qualidade).

\section{REFERÊNCIAS}

AGUIAR, Sílvio. Integração das ferramentas da Qualidade ao PDCA e ao Programa Seis Sigma. Nova Lima: INDG, 2006.

CARPINETTI, Luiz C. R. Proposta de um modelo conceitual para o desdobramento de melhorias estratégicas. Gestão e Produção, v. 7, n. 1, São Paulo, 2000.

DENNIS, Pascal. Fazendo acontecer a coisa certa. Um guia de planejamento e execução para líderes. São Paulo: Lean Institute Brasil, 2007.

TUCK, Christopher. IRON ORE. Data in million metric tons, usable ore, unless otherwise noted. U.S. Geological Survey, Mineral Commodity Summaries. Acesso em 16/06/2017. Disponível em: https://minerals.usgs.gov/minerals/pubs/commodity/iron ore/mcs-2017feore.pdf

VALE. Relatórios: sustentabilidade, financeiro e produção. Acesso em 16/06/2017. Disponível em http://www.vale.com/brasil/PT/aboutvale/reports/Paginas/default.aspx. 